\title{
Know Your INJM Editor in-Chief (April-2013)
}

\section{Vipin Chandra Kalia}

(C) Association of Microbiologists of India 2013

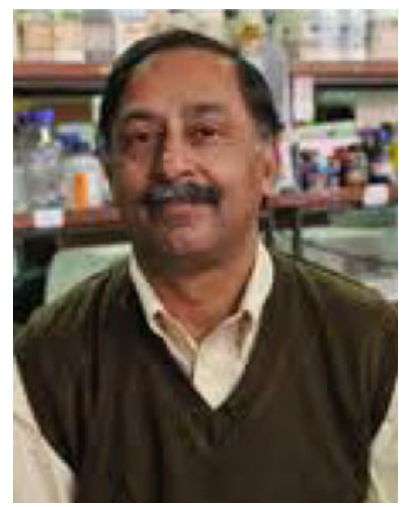

He is presently Chief Scientist, Microbial Biotechnology and Genomics, CSIR-Institute of Genomics and Integrative Biology, Delhi, is a graduate in Botany from University of Delhi and did his MSc and PhD in Genetics, from Indian Agricultural Research Institute, New Delhi. His main areas of Research include Microbial Biodiversity, Bioenergy, Biopolymers and Genomics.

His works have been well acknowledged in the areas of Bacterial Diversity, Genomics, Taxonomy, Horizontal Gene Transfer, Quorum Sensing and Quenching. His recent efforts have been concentrated towards providing bacteria with abilities to produce biomolecules having potential to be used for treating cancer, diabetes, infectious and inflammatory diseases. The work supported by Department of Biotechnology, Government of India is being carried forward by industry. His group has made contributions in understanding metabolic pathways leading to reduction in environmental pollution through complete degradation of biowastes with concomitant production of bioenergy (hydrogen) and biopolymers (bioplastics). His innovative research works are targeted towards efficient economical and eco-friendly approaches to societal problems especially waste management and energy crisis. Dr. Kalia has published nearly 60 articles in leading international journals with high impact factor and has 11 patents to his credit, including those granted in USA and UK. He has guided 11 students for their PhD and a few hundred Postgraduate students. He has travelled across the globe as Visiting Professor and as Research Scientist to several Institutes and Universities. He is a fellow of several scientific societies and served various committees including National Scientific Advisory Committee Member of the Department of Biotechnology, Government of India. He is associated with several International Journals as Editor and Reviewer. He has been a Life Member of Association of Microbiologists of India (AMI) since 1994, participated in AMI conferences and activities. Since 2007, he has been Editor and Associate Editor of Indian Journal of Microbiology (IJM). It is with pride we state that in view of his excellent contributions made in the field of Microbial Genomics and Microbial Biotechnology, Dr. Kalia has been awarded the Fellowship of AMI since 2012.

\footnotetext{
V. C. Kalia $(\square)$

CSIR-Institute of Genomics and Integrative Biology, Delhi,

India

e-mail: vckalia@igib.res.in
} 